\title{
Editorial
}

\section{El límite esencial de la gestión demócrata cristiana}

Recientemente el mensaje del Presidente Duarte fue leido a la Asamblea Legislaliva en medio de acontecimientos y de reconocimientos de realidades nada favorables a su gestión. Primeramente, la derrota de la Democracia Cristiana en las elecciones de marzo pasado habla fortalecido las ya existentes perspectivas negativas sobre el futuro del partido en las próximas elecciones presidenciales de marzo de 1989 y sobre el futuro de su proyecto politico en marcha desde 1980. En seguida, las asplraciones presidenciales de algunos de sus miembros, aunado a la derrota de marzo, resquebrajó al partido en una lucha interna que progresivamente fue tomando mayores dimensiones. Finalmente, la sorpresiva notificación de la enfermedad del mandatario y de la gravedad del caso descargó desconcierto sobre lo que podrla ocurrir en el ano restante de su período presidencial, especulándose sobre la capacidad de su sustituto, el Vice-Presidenle Rodolfo Castillo Claramount, para manejar efectivamente la situación, y se llegó hasta rumorar un posible golpe de estado.

Esle conjunto de aconteclmientos fue desarrollando la percepción en una buena parte de la población de que el proyecto Democrata Cristlano ya nada substancial podría aportar en el futuro cercano. Esle reconocimiento impregna el mensaje del presidente, cuando evalúa con cierto lamento la globalidad de los resultados de su gestión: "la ausencia de vientos favorables y de persistentes adversidades a lo largo de la rula, contribuyeron a impedir que realizaramos la travesla de acuerdo a nuestros elevados propósitos".

La alimación anterior tiene dos dimensiones para reflexión. La primera, el reconocimiento de lo limitado de los logros alcanzados; la segunda, la de las razones que el Presidente encuentra para juslificar estos resultados. Nos ha parecido más importante discutir aquí el segundo 
aspecto, el de las causas Justificativas.

Contrario a la tesis del Presidente nos parece que las causas que impidieron el alcance de los "elevados propositos" no tueron clrcunstanciales, sino que se encomtraban en el proyecto mismo, que aún con vientos más favorables la estrategia se constitula en incompatible con los propósilos, al menos con bs expllcilos.

En el mensaje inaugural de su periodo presidencial el Ingeniero Duarte se refirió a los cinco objetivos, por los cuales trabajarla duramte los cinco anos siguientes. Ellos fueron: la pacílicación, la participación soclal, el desarrollo económico, los derechos humanos y la independencla. Ciertamente, estos objetivos constituyen en sl mismos "elevados propósitos" y nos parecen no sólo válidos, sino necesarios, to que aqul nos interesa senalar es que la estralegia puesta en marcha no conducla a senlar bases firmes para volverlos viables.

Sertar las bases para ir acercandonos a la pacificación requlere de algunas premisas. En primer lugar, el reconocimiento del grado de polarización de los sectores sociales; en segundo, el reconocimiento realista de la fuerza alcanzada por los sectores en confflicto; y en tercero, la ejecución de un plan de pacificación con los mecanismos operativos y los objetivos bien delinidos, que convenza a las distintas fuerzas que carninando en la dirección propuesta lograrán realizar de mejor manera los intereses por los cuales luchan. Un plan, por ejemplo, en donde los sectores laborales encuentren los fundamentos que les garanticen mayores posibilidades de compartir el producto nacional contorme a sus necesidades y de incidir en las decisiones económicas que los afectan directamente; un plan, en donde el FMLN encuentre que realistamente puede lograr una razonable participación en el poder politico, que le permila como fuerza política incidir significativamente en la orientación futura de la sociedad salvadorena; un plan que muestre a los capitalistas que sus intereses económicos pueden incluso potenciarse en una sociedad más participativa, que sus intereses no están indisolublemente unidos al sometimiento de las mayorias a la extrema pobreza y a la desesperanza.

Un plan de consenso como el descrito presupone la vigencia de dos elementos: primero, el cumplimiento efectivo del quinto de los "elevados propositos" del Presidente, la independencia, para que se imponga el inlerés nacional en medio de la crisis; segundo, la posesión de poder real trente a la Fuerza Armada, para lograr una negociación real como un asunto de interés nacional.

La ausencia de estos dos presupuestos ha constituido el limite mismo del programa de la Democracia Cristiana.

En primer lugar, porque la condición de posibilidad para que la De- 
mocracia Cristiana alcanzara el poder dependió del apoyó polílico de la administración norleamericana; en segundo lugar, porque la viabilidad de su gestión pasó a depender del apoyo económico masivo norteamericano, el cual mantuvo en los últimos anos la economía salvadorena a flote. En ningún perlodo hislórico desde nuestra independencia se observó tanta dependencia del gobierno de Estados Unidos; tal grado ha alcanzado este hecho que la recuperación de la soberanla nacional ha sido levantada como bandera política por todos los sectores de oposición, incluyendo la derecha, su tradicional aliado. De aqul que los "elevados propósilos" fueron establecidos no dentro de un plan elaborado sobre la base del interés nacional, sino dentro de un plan detinido a partir del interés norteamericano, establecido como el logro de la paz destruyendo, aunque sea en el largo plazo - la guerra de baja intensidad-a la oposición armada. En tercer lugar, porque la ausencia de poder real, no permitió obtener de la Fuerza Armada más que algunos cambios caremes de profundidad, aceplados en la medida en que la instltución comprendió que estos eran indispensables dentro de una estrategia dirigida a su fortalecimiento y al debilitamiento del FMLN, pero consciente de su capacidad de retrocederlos en el momento en que se percbiera en ellos una amenaza para su propio poder.

Han sido estos y algunos otros cambios los que se han presentado como los logros de la gestión demócrata cristiana: el mejoramiento relativo en el respecto a los derechos humanos, lo cual en aquel primer mensaje lo estableció el Presidente como el objelivo de "controlar los abusos de autoridad y la violencia de las extremas, tos escuadrones de la muerte y todos los problemas de injusticia y prepotencia que se manifiesten"; y la relativa apertura de espacios a la participación política. concebido como el logro de "la libre emisión del pensamiento, los derechos individuales y sociales".

SI uno indaga acerca de los programas con los cuales se luchó sistemáticamente por eliminar los escuadrones de la muerte y por transformar la estructura de la justicia en El Salvador, no se encuentra mucho. Entonces, la pregunta ¿qué se hizo para alcanzar estos logros? no tiene respuesta clara. El recrudecimiento reciente, reconocido por el presidente en su mensaje a la Asamblea, de los "fatidicos escuadrones extremistas, cuyos resabios parecieran lomar nueva vida", es confirmación de nuestra tesis.

La ausencia de poder real frente a la Fuerza Armada, se hizo evidente en el proyecto de separación de los Cuerpos de Seguridad. Aqul, la Fuerza Armada no solo vetó el proyecto sino que también logró la remoción del sub-secrelario de Seguridad Pública que habia impulsado dicha reforma. 
Las amenazas continuadas durante los últimos meses sobre un posible golpe de estado más recientemente denunciado por altos dirigentes de la Fuerza Armada, conslituyen un serio cueslionamiento a la llamada profesionalización institucional y relalivisan las interrogantes que el presidente abrió en su último mensaje a la Fuerza Armada: "¿Quién dudaría hoy de que la Fuerza Armada ha cambiado? ¿Quién puede negar que la Fuerza Armada ahora trabaja junto a su pueblo?

Finalmenle, la vinculación sistemática de loda reivindicación laboral con la subversión, muestran la vigencia de los mecanismos tradicionales de eliminar la participación social del sector obrero.

En este semtido, creemos que es cuestionable que hayan sido la "ausencia de vientos lavorables y de persistentes adversidades a lo largo de la ruta, (lo que haya contribuido) a impedir (la realización) de la travesia de acuerdo a (los) elevados propósitos".

Hoy, pues, que se renuevan los impulsos por la paz, hoy que se hacen esluerzos por involucrar directamente en estos debates a un mayor número de sectores sociales, es más urgente que nunca identiticar aquellos límiles esenciales que convirtieron los esfuerzos de paz en el pasado en diálogos vacios de contenido. 